\title{
PROJECT MAKING in Elementary Science
}

By

GRACE FISHER RAMSEY

Associate Curator, Department of Education

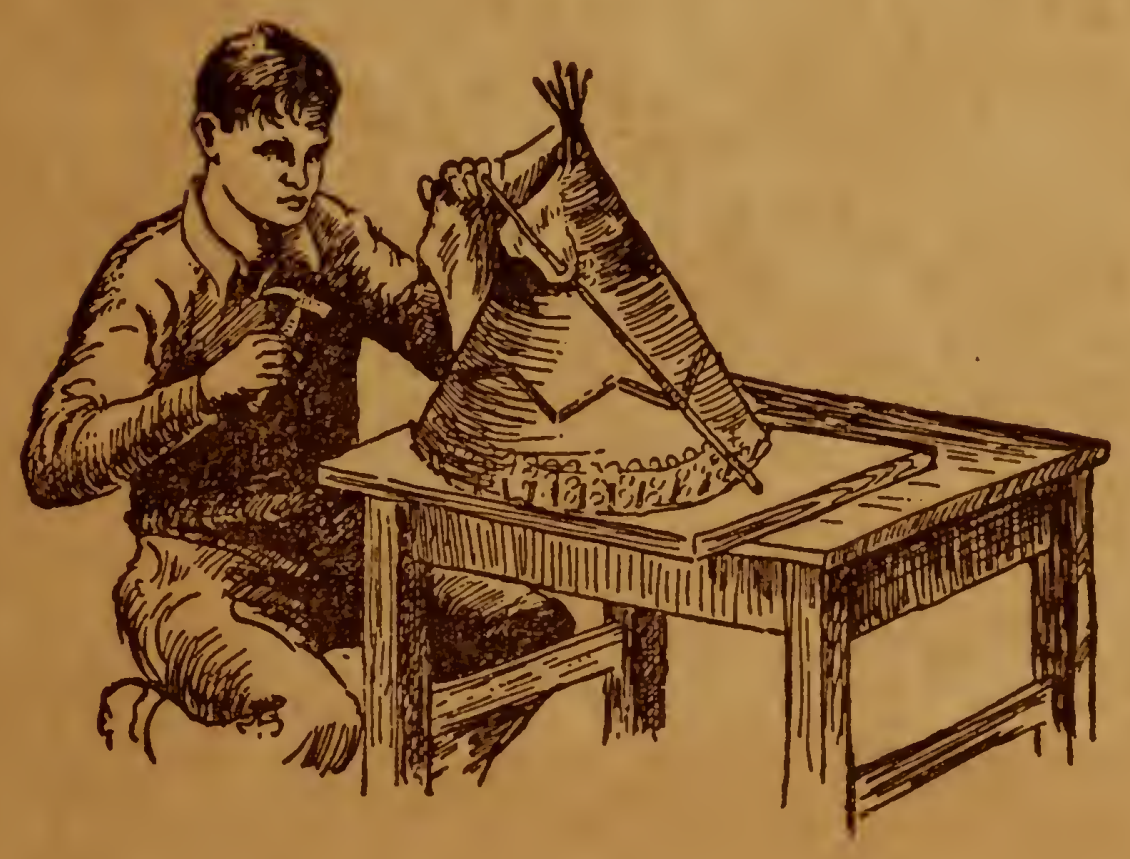

SCHOOL SERVICE SERIES, 1934

$\because 0.9$

Department of Education

THE AMERICAN MUSEUM OF NATURAL HISTORY 77th Street and Central Park West - - - New York, N. Y. 



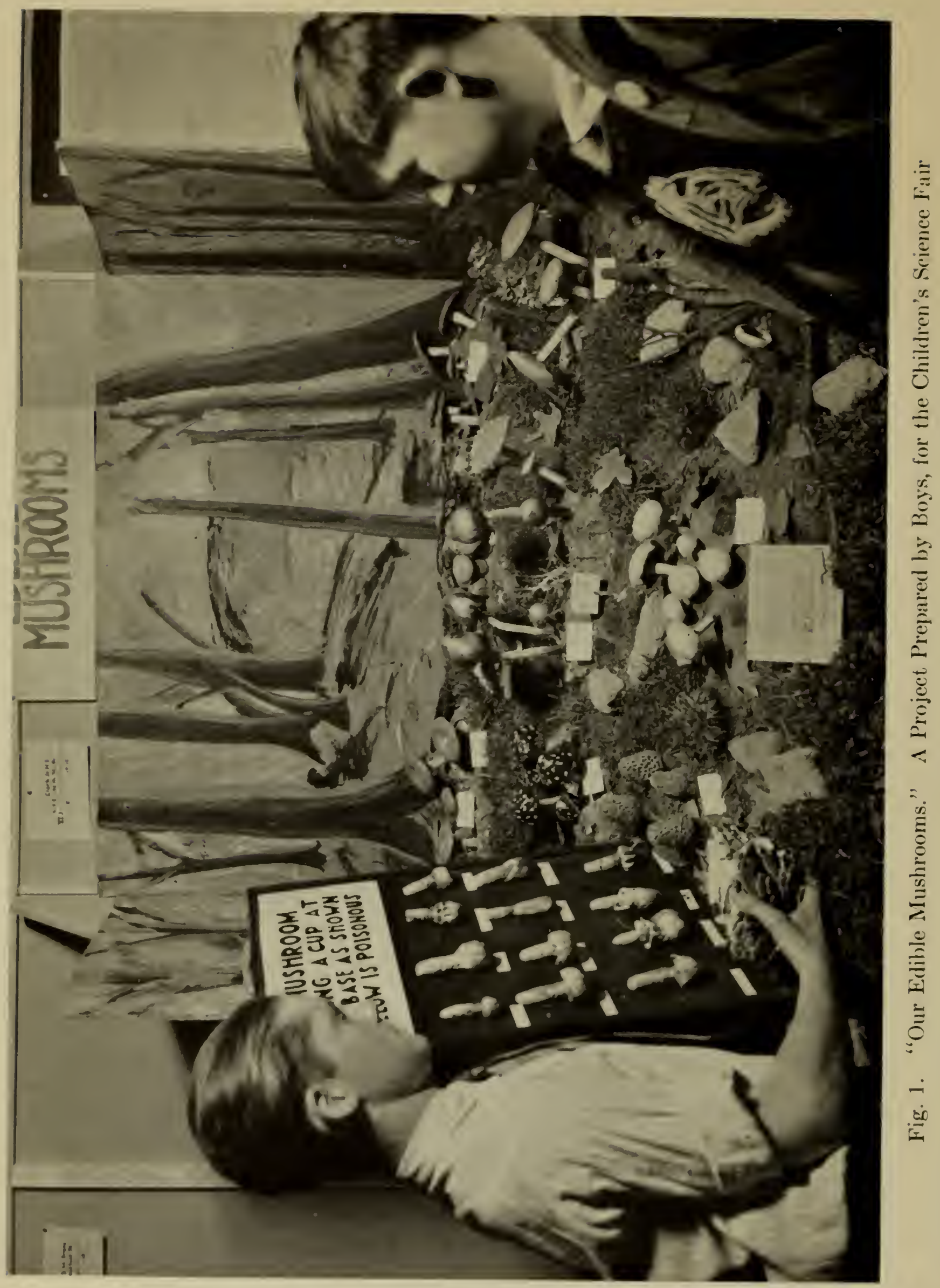




\section{PROJECT MAKING \\ IN ELEMENTARY SCIENCE}

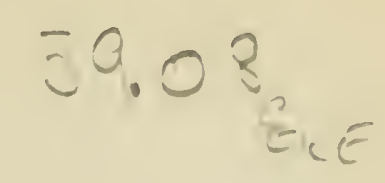

GRACE FISHER RAMSEY

Associate Curator, Department of Education

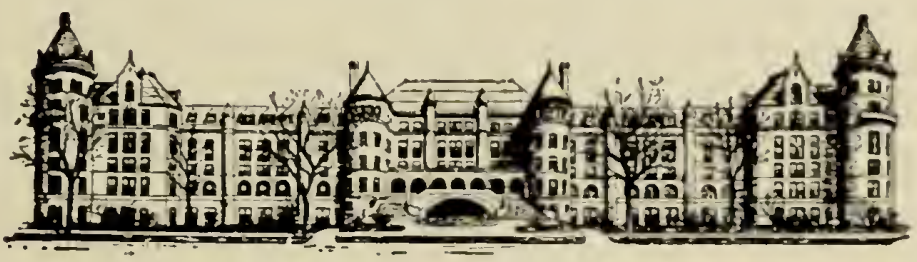

SCHOOL SERVICE SERIES is a 1934

Department of Education

T'HE AMERICAN MUSEUM OF NATURAL HISTORY 77th STREET AND CENTRAL PARK WEST NEW YORK, N. Y. 
$34129743-\operatorname{Tan} 3$ 


\title{
PROJECT MAKING IN ELEMENTARY SCIENCE
}

\author{
By Grace Fisher Ramsey \\ Associate Curator, Department of Education
}

$\prod$

HE complexities of our modern civilization cause many children to lack that guidance from direct observation which the cave boy of Paleolithic times secured from his parents who taught him how to fashion flints over the open fire. But the minds of our children are the same today as they were in Paleolithic times. They need the same direct contact with things and natural phenomena which their cave ancestors had. This contact with nature and the phenomena of their environment may be given our modern boys and girls through an effec-

\section{Function of Projects-in Elementary Science}

tive program of science instruction if such a program at all times emphasizes pupil experience both in the subject matter and the method of instruction. 'The framework of a plan in elementary science should be so flexible that it can provide for the immediate use of the children's discoveries and experiences. If a teacher is sympathetic and uses initiative, he can so direct the children that they 'an work out for themselves science projects which will illustrate fundamental ideas of science far more important to them than any textbook lesson.

Science projects often come as a response to need in the minds of children. They reach a stage in the development of a unit of work where they feel an urge to express some phase of the unit. For young children, an intimate appeal is possible and important. Whatever they can see, hear, or touch fascinates them. Everything is new to them. At the right time, the making and using of visual-sensory projects will aid in clarifying their ideas and give them a desirable opportunity for self-expression. And for sheer enjoyment, there is nothing to equal the fun boys and girls have in creating their own models.

Nor need any teacher ever hesitate to allow children to work out their ideas because of the apparent cost of construction. An ingenious Use of Everyday Materials teacher ean help, if the boys and girls need such help, in finding ways of using all kinds of materials at little or no cost in the preparation of their projects. Expensive and complicated apparatus has no place in elementary science work. A few tools, plenty of bottles, jars, glass tubing, old window shades (to serve as charts), bits of cord, old newspapers, discalded cardboard, left-over paint, and tin cans have endless possibilities for elementary science projects. The homes of the children, the ten-cent store, the drug store, the waste heaps in any department store, printer's 
shop, carpenter's shop, or hardware store, are excellent and inexpensive sources of supply. Let the girls and boys solve everyday problems with everyday materials.

For the past thirty years the American Museum of Natural History has been supplying the schools of New York City with circulating collections to aid in nature study, general science, and elementary science work. In the preparation of these collections certain techniques have been developed which are applicable to many types of projects. This pamphlet, which describes these basic techniques and gives suggestions for using simple materials in making projects to tell the story of elementary science clearly and concisely, has been prepared in response to many requests from teachers all over the country. Special thanks are given here to the assistance received from John Orth, a preparator in the Museum's Department of Education, for descriptions of many of the techniques which he has developed in making circulating collections for the Museum.

To start with some of the common experiences of children, we find mayonnaise jars containing a bit of cotton soaked in carbona and covered Insect with a piece of blotting paper make excellent jars for killing Projects insects painlessly. Old tin cigarette boxes make very good places to store these moths, butterflies, and other insects gathered on their field trips. Similarly mayonnaise jars may be used for moistening insects' wings just before arranging them on the spreading boards preparatory to mounting. But before we can use spreading boards, we must collect our insects. Even in crowded cities, it is possible to collect many species of insect life. What an afternoon of fun and value your group of boys and girls can have on an insect collecting trip!

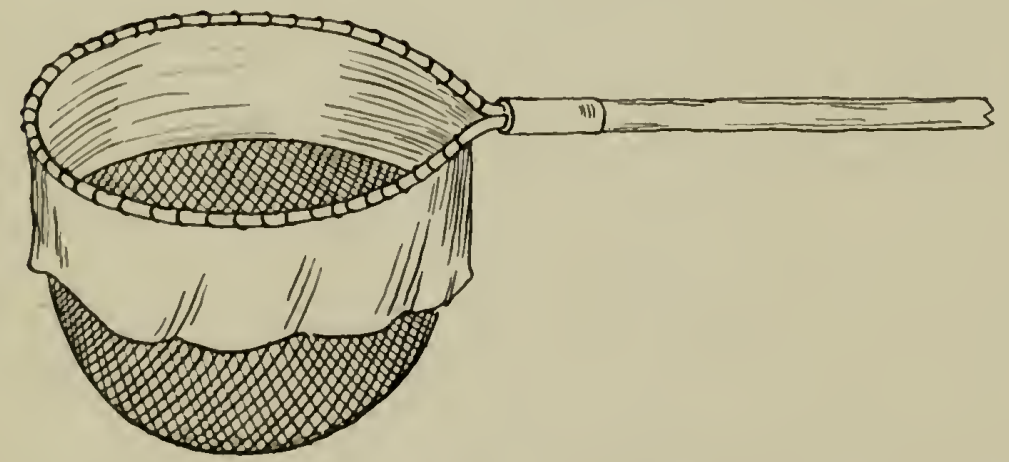

Fig. 2. Dip Net for Aquatic Insects

Aquatic insect life can be collected with a dip net made with a bag of heavy, fine-meshed brussels net, about six inches deep and protected around the sides and upper edges by a heavy unbleached muslin curtain. Where the water is flowing swiftly, the net should be held against the 
bed of the stream while stones are moved just above the net. Many forms of insect life will float on the water and be caught in the net. The underside of stones or sticks are also good places to look for other aquatic insects. Nearly all such forms of insect life may be preserved in eighty per cent alcohol. Here again, mayonnaise jars are called into use.

Collecting land forms of insect life by sweeping a net rapidly over grass and weeds is generally satisfactory if the pupils have made themselves a good sweeping net at least twenty-four inches deep, of lieavy unbleached muslin attached to a ring frame of heavy, coppered steel wire with a diameter of about twelve inches and provided with a stout handle of wood. Rotten logs are good places in which to dig for beetle larvae; others may be captured by moving sticks and stones. The simple insect killing jar previously described will answer all ordinary purposes.

In addition to keeping the date and locality of capture with the name of each specimen, have the collectors add what the insects were feeding on or what they were doing. Insects should be arranged or mounted on the setting board as soon af ter they are collected as possible, while they are still relaxed. Cigar boxes make very good pinning boxes for an insect collection if a layer of corrugated paper or cork is fastened to the bottom. Special insect pins, size 3, should be used in mounting. In case any of the insects are too small for pinning, cut out triangular pieces of heavy glazed paper, to the tip of which the insects may be glued with white shellac.

Butterflies and moths make a nice looking collection if all four wings are expanded nearly at right angles to the body. Detailed directions for making and using the setting board, as well as other helpf ul advice may be found in the pamphlet "How to Collect and Preserve Insects" by Frank E. Lutz, Guide Leaflet Series No. 39, The American Museum of Natural History.

All children are interested in making lifelike representations of vivid descriptions they have read, or of what they themselves have seen. A Habitat habitat group accurately reproducing, often in miniature, a Group Projects scene in real life, is not too difficult for your boys and girls to construct very successfully. Such a group can be made with natural or artificial groundwork, a painted backiground, and specimens of the real life if it be small, as some birds, or insects-life histories of dragon flies or butterflies and moths. Or miniature models of mammals modeled in plastiline can be used. 
The first thing to do in constructing such a habitat group is to have the children plan very carefully what they wish to represent and draw a sketch to show how the accessories and forms of animal life are to be arranged in the group. Community life of animals can well be shown by means of a small group which reproduces their natural habitat. The beaver is an animal which interests childien so greatly that they are most enthusiastic over the construction of a habitat group in miniature, showing the winter lodge with its dome-shaped roof rising above the water in a stream which has been flooded by the beaver dam just below.

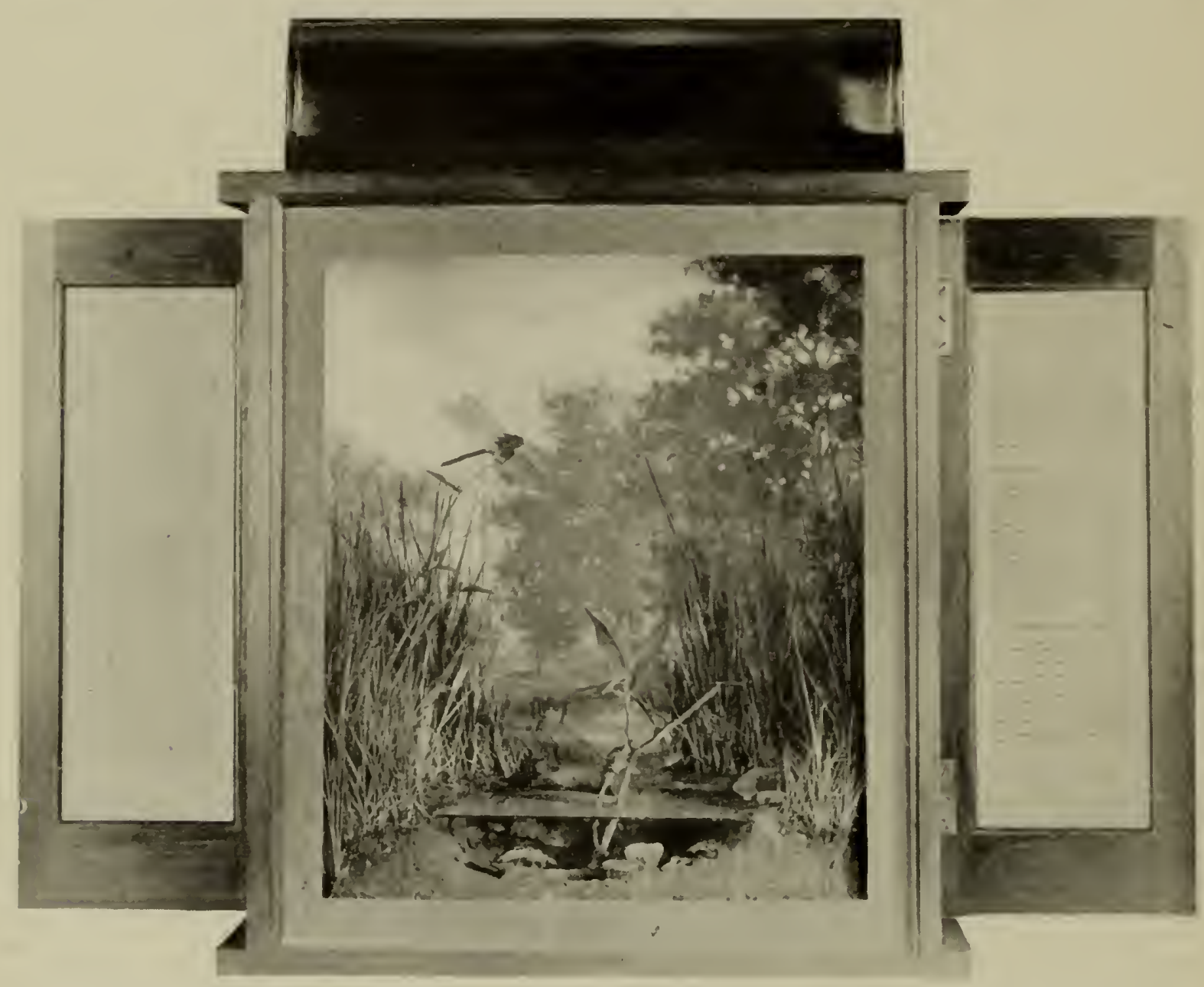

Fig. 3. Life History of the Dragon Fly.

A SMALL HABITAT GROUP

The life history of the dragon fly can be worked out nicely and without a great amount of time. In the group shown in the illustration above, the voracious nymph, with its amazing lower lip ready to grasp an unsuspecting insect, may be seen through the glass front and also through the glass used to represent a section of a pond, while another nymph has crawled up the stem of a water weed and is molting for the last time, emerging in the adult form with its beautiful, gauzy wings. Just above, 
another adult is fying over the weeds, ready for its prey of mosquitoes and griats.

The construction of a habitat group to show the interdependence of plant and animal life is a project that will require much careful thought and plamning by your more adranced pupils, but when completed, they will surely rote it a most worthwhile activity.

Material for a bird habitat group must be griven careful consideration as so many of our birds are protected by both State and lecleral Laws. Usually, it is only museums that can secure a permit to use some of these protected birds for public exhibition purposes. Have the boys and girls secure a list of the protected birds and plan their group so none

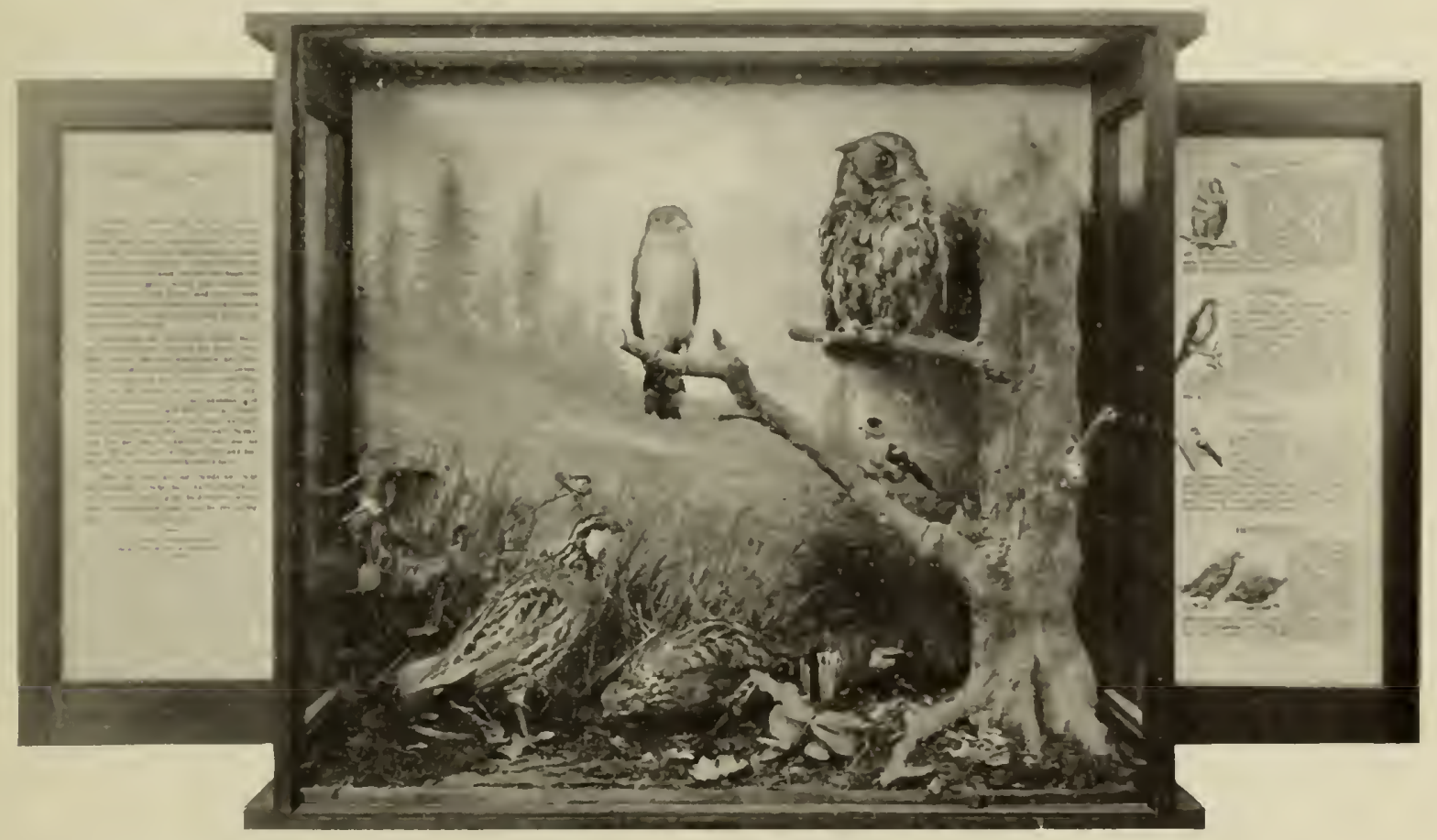

Fig. 4. "Birds That Are Our Friends"

of these will be included. The taxidermy of birds is not described here as it is so clearly given in many books on the subject, also in the pamphlet, "The Preparation of Birds for Study," by James P. Chapin, Guide Leaflet, No. 58, published by The American Museum of Natural History.

\section{CONSTRUCTION OF A SNALI HABITAT GROUP}

For the groundwork of a habitat group the first essential is a smooth board cut to the desired size and one-half or three-fourths of an inch Groundwork thick. This will form the foundation for the entire group. In some cases the groundwork can be built on the smooth board but very often an irregular surface is desired to provide for a pond or a slope of ground. This can be produced in several ways. Small pieces of thin wood or cardboard may be cut into irregular shapes 
and tacked on to the baseboard. The edges should then be beveled to form a gradual slope. If many irregularities of different heights are desired, a piece of fine screening propped at intervals by pieces of wood can be tacked to the baseboard and then covered with plaster of Paris. Fairly thick plaster should be worked well into the screening and allowed to dry completely. Then apply a coat of shellac to its surface.

The effect of earth can be made by coating the groundwork with some strong glue and sprinkling fine sifted earth on the wet glue. Pat this loose earth into the glue and allow it to dry. The surplus earth can then be blown off or shaken off. Another method is to omit shellacing of the plaster and apply fine earth soaked in a solution of glue and water, one part glue to eight parts water. First size the plaster with glue sizing before applying this mixture. Then smear the earth and glue mixture over the surface, tamping it down with a brush. Bits of leaves can be added to give a very realistic appearance.

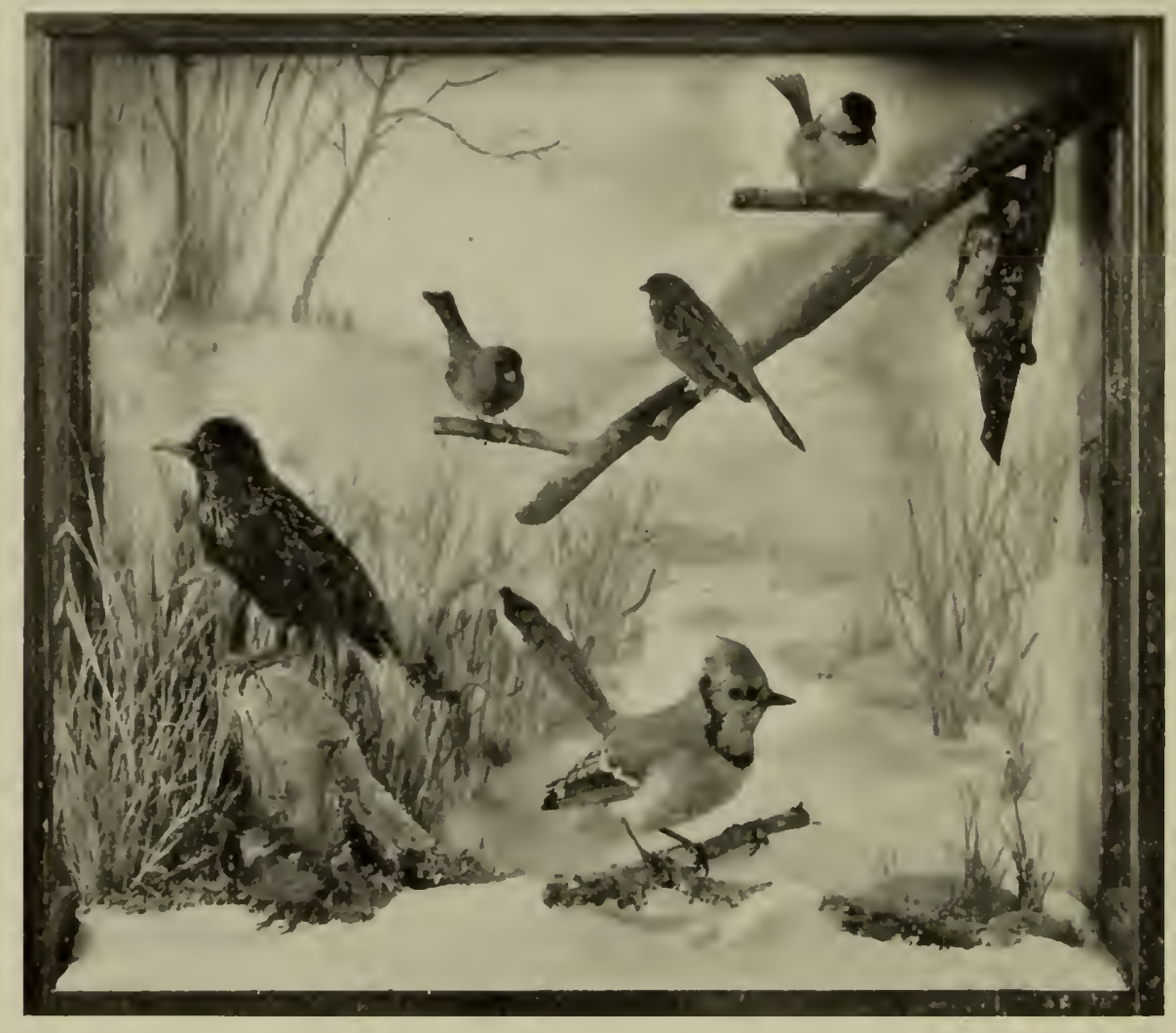

Fig. 5. "Winter Bird Neighbors."

If you wish the effect of snow, ordinary paraffin can be melted and sprayed over the groundwork by dipping a stiff scrubbing brush into hot paraffin and then drawing a stick at right angles across the ends of the bristles. Very natural effects can be produced in this way.

In case a pond is to be a part of this habitat group, glass can be used. A piece of old window pane will answer the purpose nicely. Pieces of thin wood or compo-board should be built up at the sides of the base- 
board and cut so as to taper off and thus give a gradual underwater slope toward the bottom of the pond. Shellac mixed with fine earth, to give a fairly heary consistency, can be applied to the underwater portion and allowed to dry thoroughly. As this dries, it gives a wet, muddy appearance which is very realistic. Now place the glass in position and treat the surrounding ground with glue and fine earth as stated above. It is usually best to leave the final coating of earth until the construction of the group is well started. This practice varies with the type of materials to be used in the group and should be considered in the first planning.

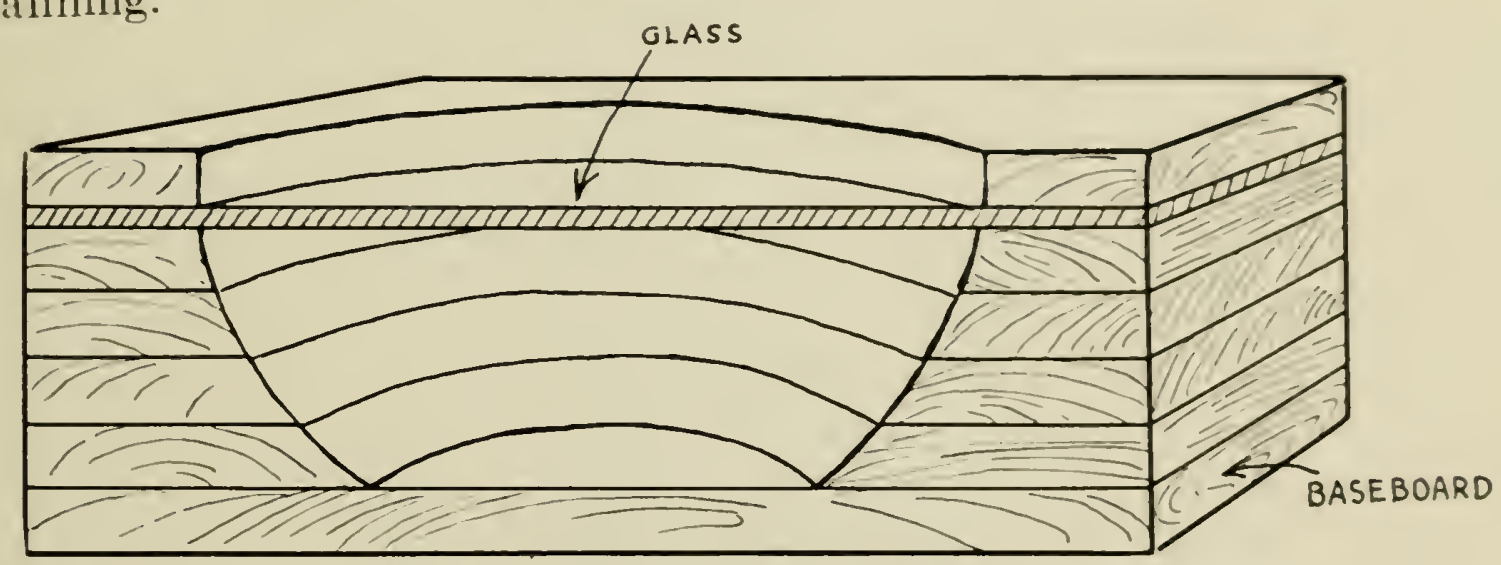

Fig. 6. Diagram of Construction Work for Habitat Group).

In planning the accessories for the group, the boys and girls should realize that often some substitute must be found which will initate the Accessories real thing. This is especially necessary when the habitat group is to represent life in miniature. In the case of grass, many substitutes can be used-short lengths of hemp, flax, bristles, fine dried grasses, etc. Fine excelsior is usually the most satisfactory material even if the scale of your group is an inch to the foot. The excelsior can be pulled into almost any shape desired. It can also be curled and will take colors well. Small holes should be drilled into the groundwork wherever the clumps of grasses are to be placed. Several strands of the substitute are then tied together at one end and this end is dipped into glue. Set the glue-covered ends into the drifled holes and allow to dry. When the bundles have dried in place, they can be cut to shape and colored with oil paints.

The construction of a miniature tree presents a problem rather too difficult for the children, as there is a great amount of work in creating an artificial tree which is accurate in every detail. However, there are substitutes that will answer very well in your habitat group. 'The common sponge is a favorite material to use, especially for a shrub where no trunk is necessary. The sponge can be cut into almost any shape desired 
and colored with oil paints to suit the purpose. For the trunk of a tree, a twig or branch of the right diameter (considering the scale being used in the group) may be used.

Wild Pepper-Grass (Lepidium virginicum), which has been dried and colored with oil paints, can be used for imitation trees. Other small plants that will not fall apart when dried can also be used to good advantage. If dried foliage is to be used, it should first be dried carefully. Then soak the dried specimens in hot water for fifteen minutes and immediately immerse them in a solution made by mixing two parts of formalin, twenty-five parts of glycerine and the remainder water. After the material has soaked for about half a day, remove from the solution and allow to dry carefully. It usually requires about a week for this drying but in the meantime other kinds of work can be done on the group. After being thoroughly dried, the material can be colored with oil paints. Evergreens and mosses as well as grasses can be preserved by this formula.

For a still more realistic tree, let the boys and girls search for a branch with twigs set at the proper intervals. They can cut this to size and make small leaves cut from paper and glued to the twigs with some quick drying cement or ordinary glue. If glue is used, have them pin the leaves into position until it is thoroughly dried. Here again oil paint may be used for coloring. Small pieces of colored sponge may also be used for leaves by gluing them to the twigs.

Wire of different sizes twisted into the shape of a tree and then coated with a mixture of Ambroid and plaster of Paris, mixed into a paste, will often serve for a tree. When dry, oil colors will give the effect of bark. Then the leaves can be constructed and fastened as previously described. No doubt the most attractive and accurate foliage can be made from wax. This method is very fully described in the pamphlet "Building the Museum Group" by Albert E. Butler, Museum Guide Series No. 82, published by The American Museum of Natural History.

Do not forget that a painted background is essential for the group. Indeed, it is taken for granted that this fact has been carefully considered Background in the preliminary sketch groups and that the foreground foliage in the foreground is exceptionally thick, a painted sky will do nicely for the background. But when the foliage is thin, a complete background is necessary. Either a painting may be made or a carefully selected, enlarged photograph, colored with soft tints of water colors may be used. The semi-circular background will give the most realistic effect to the group. The foreground in this case must also be made semi-circular so the background will cover the entire curved portion. Several methods 
can be used in attaching the background to the group). If the children have made the group rectangular, the picture may simply be attached at the rear and the foregound sloped up to it by means of plaster. 'This sloping is not always necessaly, depending upon the type of foreground used. If the more effective semicireular background is used, get a piece of black sheet iron and paint directly upon it with oil paints, first giving it two coats of plain white lead.

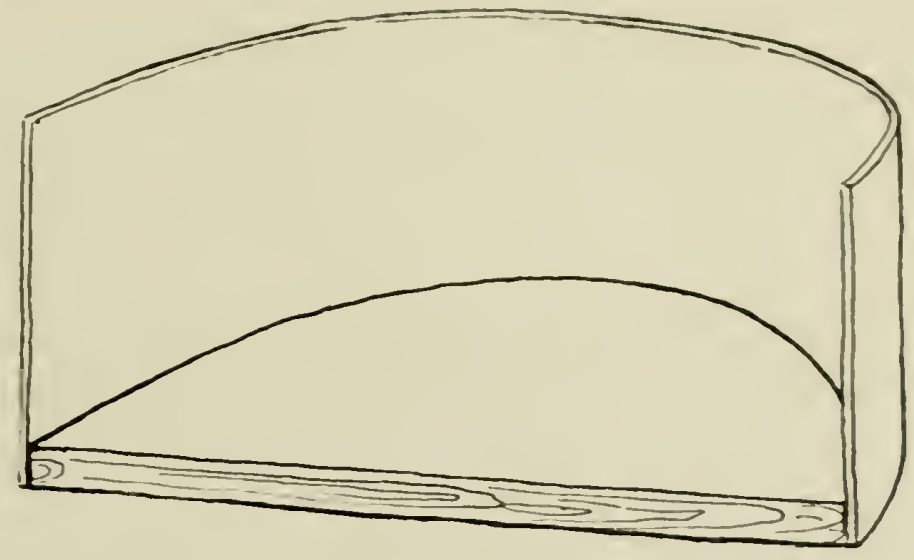

Fig. 7. Diagram Showing Semi-Circular Background.

Empty shoeboxes prove valuable in constructing simple groups in both science and the social studies. With a curved painted backiground placed in the back of the box as it is turned on its side and with figures cut from paper, colored, and fastened in appropriate positions, very realistic effects can be obtained by even the youngest children.

To protect the group from dust and careless handling, have the children place it in a straight-sided case with a glass front and the top covered with a piece of ground glass. This latter is used only if interior lighting effects are desired.

If you have electricity in your school, by all means plan to light the habitat group. A simple arrangement is to place an ordinary electric

\section{Lighting} the Group light bulb in a three-sided box directly above the group so the light will shine down even through the ground-glass top, thus being evenly diffused over the interior of the group. If raried lighting effects are desired, as the soft glow of a moonlight evening, the bright sun of midday, or the rosy tints of dawn, have the boys and girls make a simple cylindrical frame, as was done in one New York school, the sides being made of lengthwise strips of crepe paper alternating the colors of blue, yellow, and red, with one-third of the circumference being given to each color. Slip this frame over a low wattage electric light bulb and attach it to an outside knob so any child may turn it to give the special lighting effect he wishes. See Figure 3. 
Let us turn for a short time from the natural history phase of habitat groups to the preparation of a group that will be useful in the social

Habitat

Group for Social Studies

studies as well. Your pupils may have decided that they wish to construct a group containing miniature human figures and a simple type of shelter. For miniature figures, a wire armature is almost always necessary. This armature can be constructed by twisting two fairly stiff wires together at their centers. These will form supports for the arms and legs. Where the two arm wires join, another wire is twisted into place. This is used to form a brace for the head.

Plastiline can be used for modeling the figure but this remains soft for such a long time that it is not always practical to use. However, if

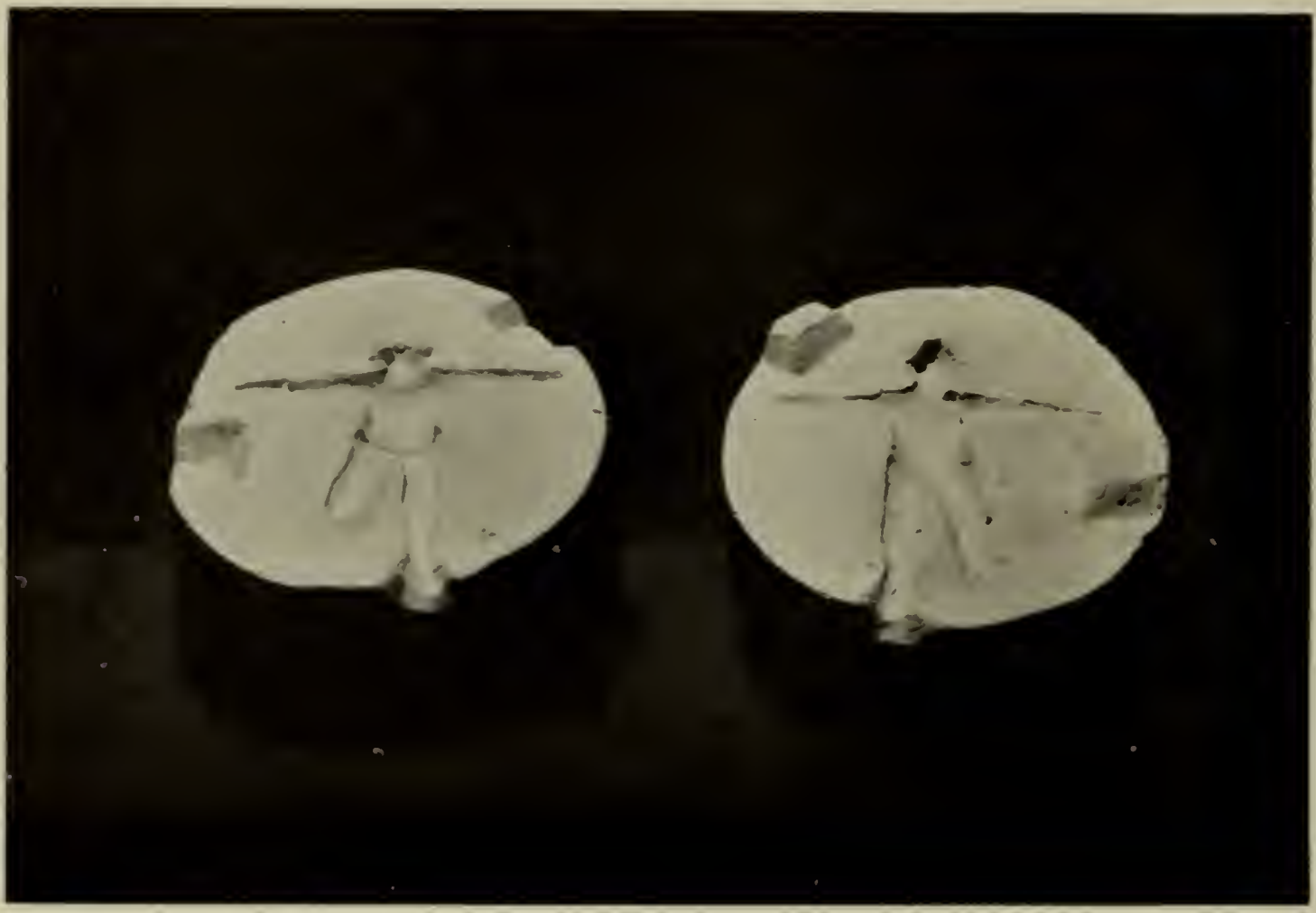

Fig. 8. Plaster Mould for Duplicating Figures.

a plastiline model is constructed, and several figures are needed for the group, a mould and a series of casts can be made from the one model. The figure should be modeled with the arms and legs outstretched. Then lay the inodel flat on its back with one-half embedded in a flat piece of plastiline around which a wall of the same material has been built to a height of at least one inch over the highest portion of the figure. Now into a mixing bowl put an amount of water equal to four-fifths of the quantity of plaster needed. Sprinkle the dry plaster slowly into the water until it has a uniform consistency throughout. Remember that plaster should always be put into the water; never pour water into the 
plaster. To obtain the best results, have the children mix the plaster thoroughly with their hands. For the purpose required here, the plaster mixture should be just thick enough to pour.

Now pour the plaster mixture into the framework prepared. After the plaster has set, the plastiline base and wall are removed, leaving the model in place, with one-half embedded in the plaster. Cut tapering holes about one-half inch in diameter and three-eighths of an inch in depth, into the surface of the plaster. These are to be used as keys in fitting the two halves of the mould together in correct relation to each other. The next step is to build a wall of plastiline around the finished one-half mould. This should be as high above the surface of the completed half mould as this half mould is thick. The surface of the plaster is now to be coated with vaseline, a thin oil, a soap solution, or clay water and plaster for the other half of the mould to be poured in. In making the soap solution, dissolve soap chips in water to make a thin syrup. The clay water is water clay considerably thinned out with water. When the plaster has set, remove the wall and gently pry the two halves apart at the seam. You can now easily remove the model, leaving only the impression in the mould. Extend the cavity made by one of the legs down to the edge of the mould on each of the halves so it may serve as a duct into which you can pour melted beeswax in making duplicate figures. When completely dry, place the mould in hot water and leare it until it reaches the temperature of the water. While the mould is soaking, the wax should be melting. When the mould is warmed, remove it from the water and dry it with a sponge or cloth. Into the cavity of the mould place a simple wire armature around which some cotton has been wrapped. Leave the wire of one leg long enough to extend down the duct to the edge of the mould. Tie together the two halves by wrapping a piece of cord around them and pour the melted beeswax into the mould through the duct. The wax can be hardened quickly by immersing the mould in cold water for several minutes. Now pry open the mould and remove the cast figure. With a warm knife blade cut away the excess wax on the one leg where the duct was used. A great number of casts can be made from the one mould and their positions changed as desired by dipping the wax figures into warm water and bending the legs or arms into the special attitudes needed in the group.

To provide for fastening the figures firmly to the groundwork, use the wire extending from the one leg. If no armature has been used for the figure, run a wire part-way up each leg. By heating the wire slightly you can force it gently up the center of the leg. Allow it to project at least one and one-half inches below the sole of the foot. As the wax hardens, the wire will be held firmly in place. Another method which may be 
preferred, is to insert a wire into the duct while the wax is still soft, making sure that the wire is long enough to reach the middle of the leg.

After this casting is finished, the figure will need some touching up. Almost any kind of a pointed tool such as an ice pick, awl, or nail will answer, although tools for this purpose are on the market. Ask your dentist to give you some of his cast-off tools. Many of them will be excellently adapted for this work. The tool should be heated and the surface of the wax smoothed out. To give the wax a very smooth surface, fine sandpaper may be used to take off the rough spots and then a soft cloth dipped in turpentine may be used for polishing. As turpentine dissolves beeswax, this cloth must be used very carefully.

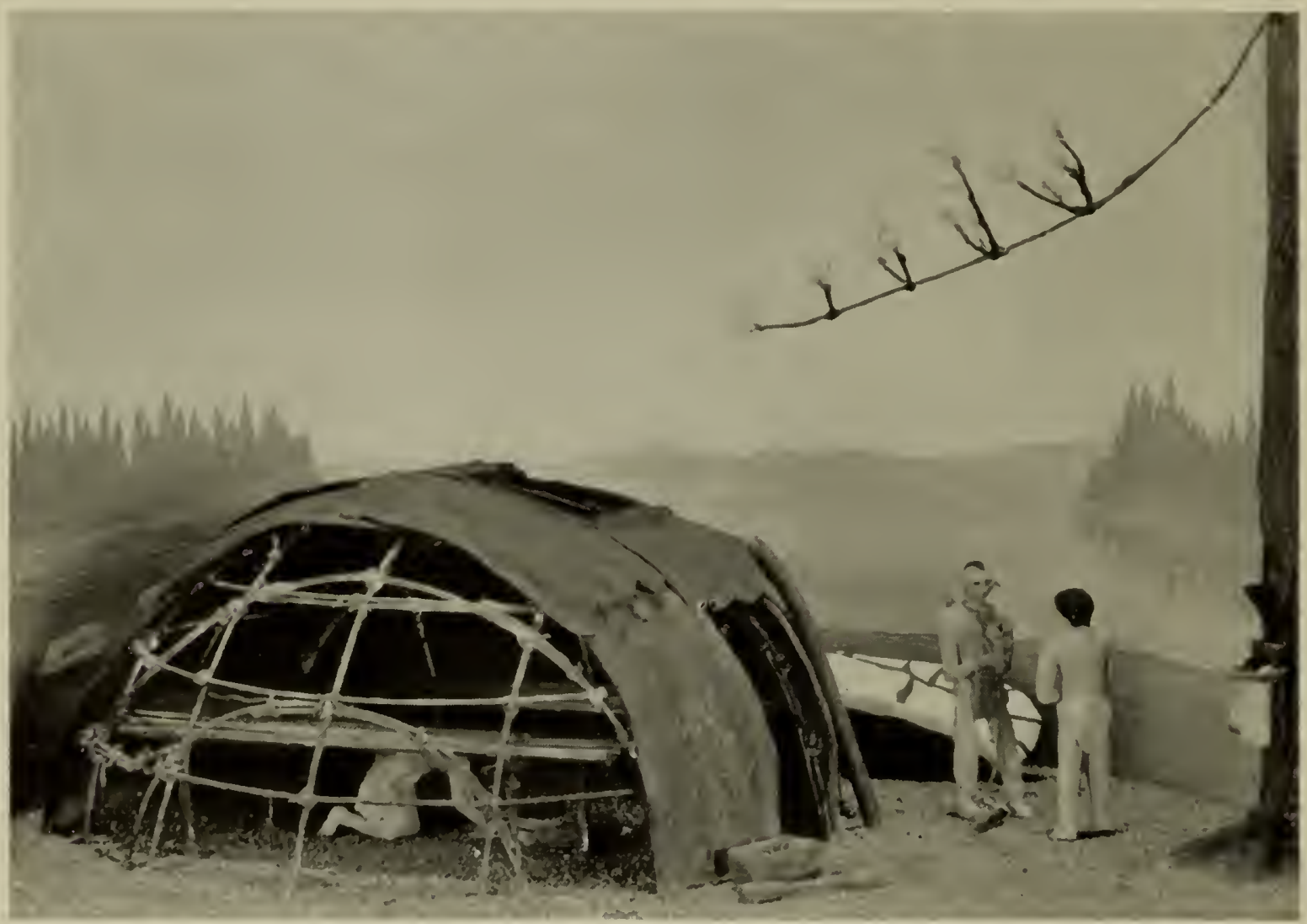

Fig. 9. Indians of the Eastern Woodlands.

Costumes can be made of porous paper dipped in wax and then put in place before the wax cools. Small pieces of cloth or fur can be used very easily. Tack these in place by softening the surface they are to cover with a hot tool and then hold firmly in place until the wax cools. When the figures are completely clothed and trimmed, paint them with oil colors.

To mount the figures on the groundwork of the group, drill two holes to correspond with the leg wires and then set the figure in place. Next bend the wires at right angles under the baseboard and elinch them together. 
For very small figures, the wire armature coated with it thin paste of Ambroid and plaster or hot wax gives fairly good results. Features and costumes may then be made on the figures by adding a bit of Ambroid and plaster mixture or wax wherever necessary. Oil paints can be used in coloring the figures.

Types of native dwellings in various parts of the world differ so much that only materials and their uses will be described here. In discussing

\section{Dwellings}

what material is to be used for a prinitive dwelling let the children realize that much care must be taken in its choice as proportion is such an important factor in the accuracy of a group.

Plaster is an ideal material for the construction of some types of dwellings such as an igloo or an Indian pueblo. A moukd and cast may be made, but a framework of wood covered with screening and then coated with plaster will often answer the purpose. Thick plaster is used for the outer coating. This should be put on in several coats. It is then worked into shape as much as possible before the plaster sets. The rough portions can be smoothed down with a knife or other tool. To imitate blocks of stone or ice, cut grooves into the surface. An ordinary wood screw used as a file is an excellent tool for this purpose. The size of the groove will determine the size of the screw to be used. A coat of shellac will give the plaster a hard surface and it may then be painted as desired.

For many dwellings, a framework of wood is necessary. 'Thin twigs or pieces of old discarded wicker furniture can be used where a rough effect is needed. Even pieces of wire coated with an Ambroid and plaster mixture can be used. When wire is being used throughout, the whole structure may be erected and then the coating applied to the wire. Oil colors will give the natural effect.

For fastening the wooden framework, a quick drying cement is useful although size must be considered as an important factor here. If the framework is fairly large, nails can be used but they should be placed so as not to be conspicuous in the finished dwelling. Often it is necessary to fasten the framework together with small strips of bark or strong grasses so it will be realistic.

Strands of flax, hemp, dried grasses, or straws from a broom can be used for thatching. Care must be taken to see that the size of these materials are in proportion to the rest of the structure. The material may be tied into small bundles or glued into strips and then fastened to the roof starting at the lowest point and working across the structure. Attach the next row so the free ends will cover the fastening places of the first row and so on until the entire roof has been covered. The actual 


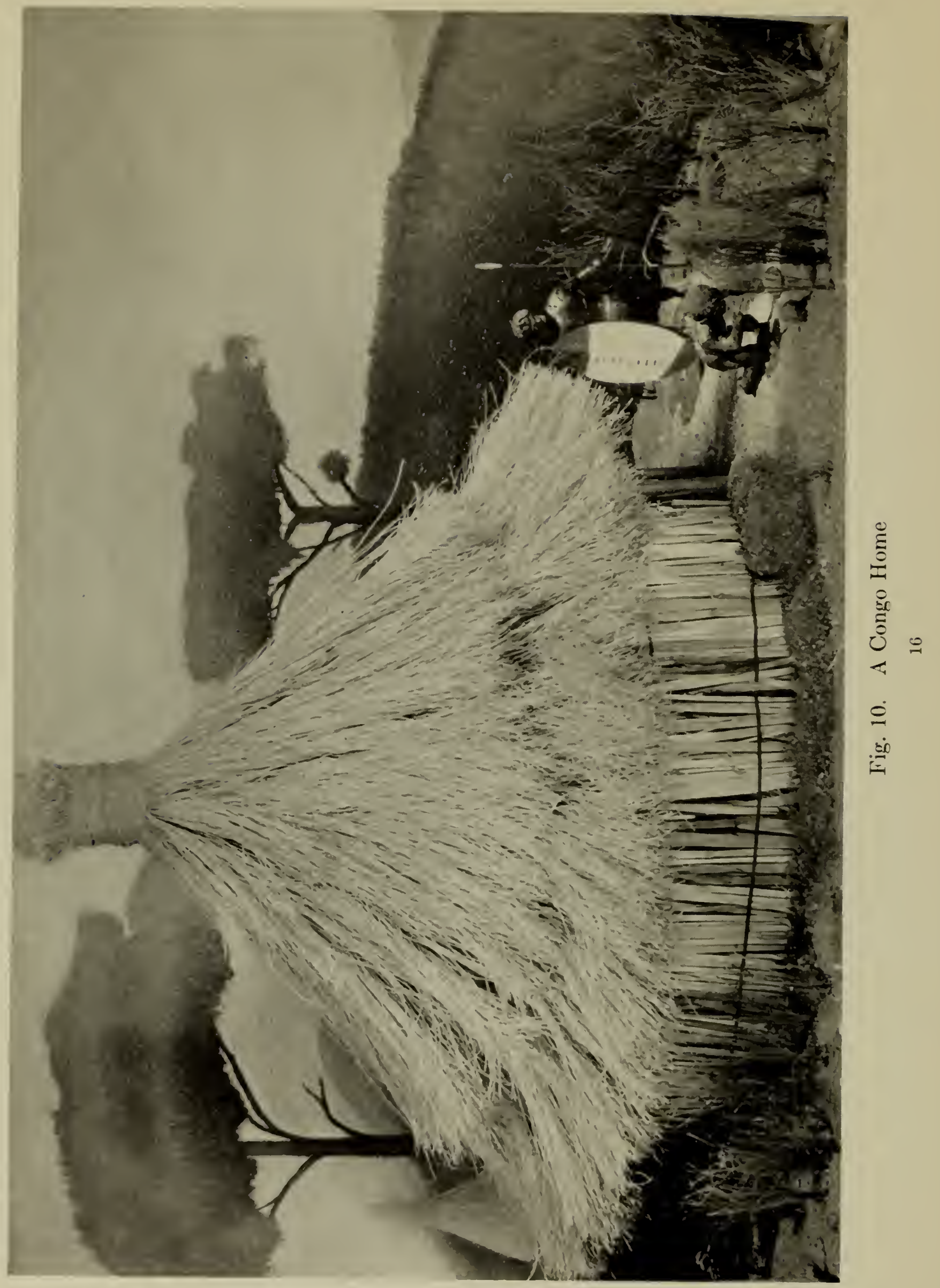


methods of attaching the that ch to the roof varies according to the type and construction of the framework.

A simply constructed group and yet one that is very cffective in showing safety and health at the seashore, was recently made by the Seashore pupils in a second grade in one of the New York (ity put)Project lic schools. The chief material used in the preparation of this group was old newspapers soaked in plaster of Paris and water. The rocks were small and irregularly shaped. They looked very well when painted in oil colors. The same material was used for making the incoming waves. 'These breakers were modelled from longer pieces of paper soaked in the mixture so a curve at the top formed the cuestsof the waves. A number of five-cent dolls purchased from Woolworth's store and dressed by the children represented grown-ups and children at the seashore. Even the Life Guard was seated in his elevated chair. Small bits of picture molding formed the benches placed at advantageous spots on the beach. Pieces of cotton were used to represent the spray dashing over the rocks at the sides. The group was completed with it background of a simple, yet effective, painting of a seascape.

A few suggestions for other groups may ke welcomed here. However, in the production of any of these activities, let the boys and girls always keep in mind the necessity of arranging their materials in such a way that they will be not merely a collection, but will tell a story that is both interesting and true.

This point is well illustrated in the rock and mineral project. Doubtless many thousands of children have made collections of common Rock and rocks and minerals. They are ako interested in what makes Mineral up a rock, although this part of the story is very seldom shown Project in their rock collection. How much more valuable such a project will be if arranged somewhat like the one shown in figure No. 11!

Among the igneous rocks shown is a piece of gray granite fistened with wire to the mount, which may be heavy cardboard, pressed wood, or other light-weight material. Below the granite specimen and fastened with Ambroid or white shellac to the cardboard, are bits of the minerals which compose the granite specimen-white feldspar, black mica, and quartz. Similarly, the red granite in the center is the same, with the substitution of pink feldspar. The trap rock is accompanied with white feldspar and hornblende; the gneiss with white feldspar, quart $z$ and black mica; the mica schist with quartz and black mica. 'The relation of sedimentary locks to their metamorphic equivalents is also shown by using a vial of sand for the loose sediment, sandstone for the consolidated 
sediment, and quart zite for the metamorphic equivalent. Others shown here are as follows:

\begin{tabular}{lcc}
\multicolumn{1}{c}{ Loose Sediment } & Consolidated Sediment & Metamorphic Sediment \\
Marl & Limestone & Marble \\
Clay & Shale & Slate \\
Clay (mud and sand) & Shale & Schist \\
Gravel & Conglomerate & Gneiss
\end{tabular}

As rocks intergrade more or less, only typical specimens should be used and none smaller than one and one-half inches in circumference.

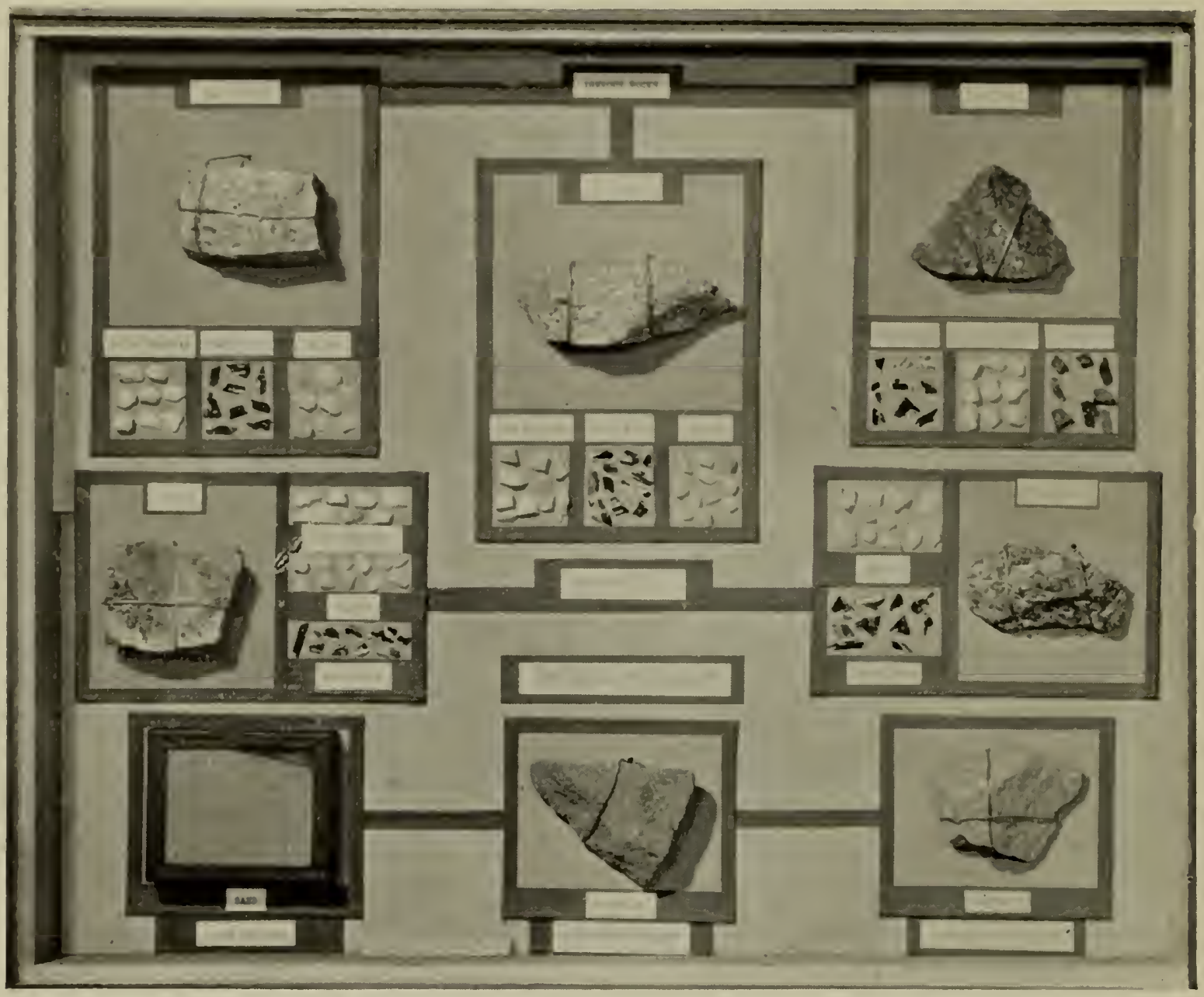

Fig. 11. Rocks and Their Minerals.

Each specimen is fastened securely to the heavy cardboard by two pieces of wire. Brass belt lacing is best to use because it does not stretch as ordinary copper wire. When the specimens are especially heavy, they are first fastened with cement (Dupont cement or Ambroid) and then wired. The loose material such as sand or gravel is placed in small glasscovered boxes or screw-capped bottles.

And have you heard of the P-C Railroad whose construction may be easily worked out by your more advanced students? One of the members 
The P-C of the Museum's staff in Education' describes this railroad Railroad Project as follows: "The most unique railroad in the world is one which has taken millions of years to construct and still is not constructed. It is operated on a distinctly cooperative basis and controlled by a power unknown, umappreciated, "uncanny'- the Power of the Laws of Nature. The railroad is called the ProtozoaChordata Railroad, and has millions of miles of tracks, which are not tracks, millions of trains which are not trains, and stations which are not stations. Precisely it is an ANIMAL, Railroad, owned and operated by one large Kingdom in which each living organism plays a part as

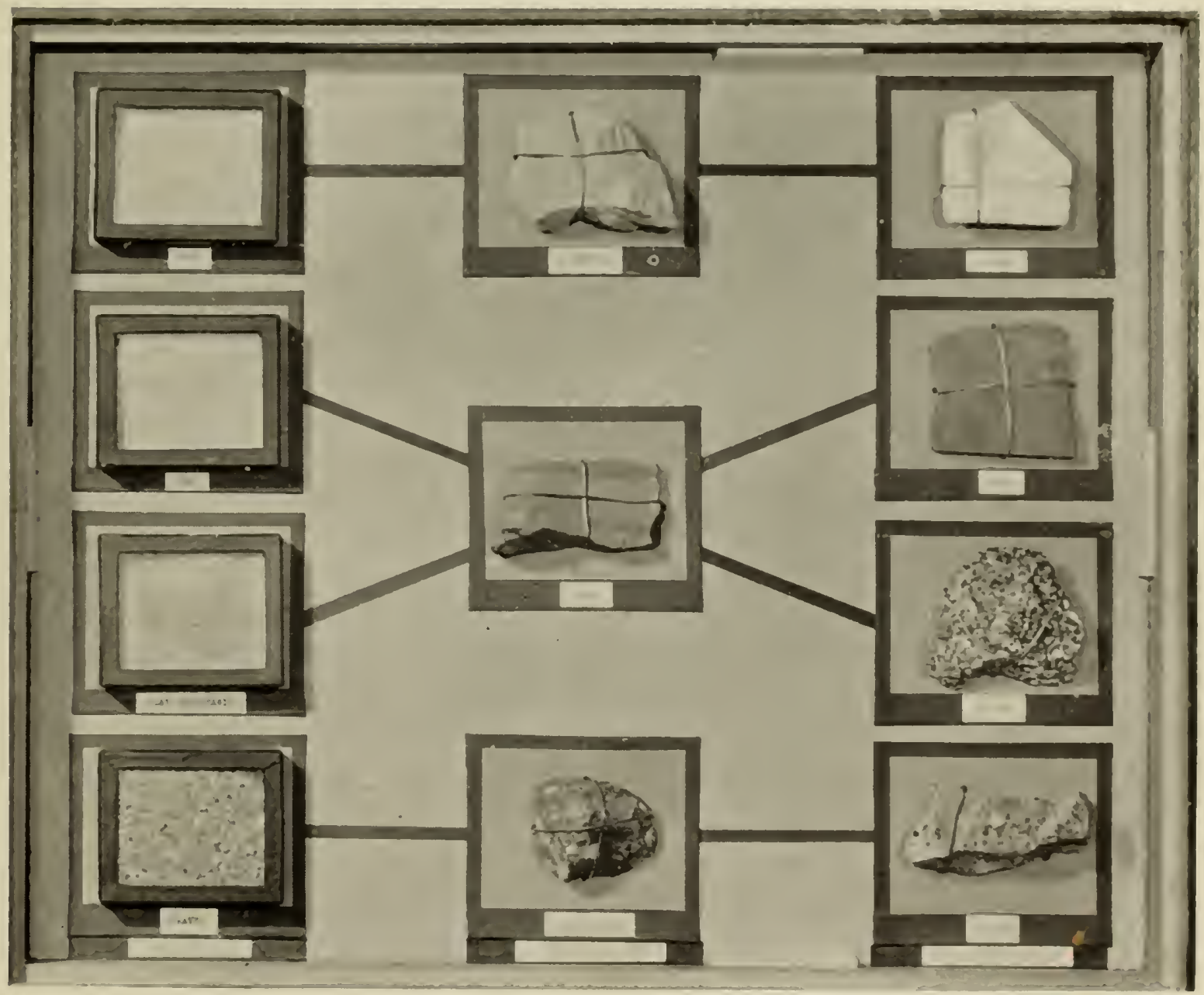

Fig. 11A. Relation of Sedimentary Rocks to Their Metamorphic Equivalents

important as the proverbial 'link to the chain.' It suffers losses and tragedies and dissension: it enjoys growth, power, and magnificence. Its 'Registrar' keeps his finger on the public pulse and chalks up for Science and Posterity perhaps a new station in the form of a new species, perhaps a flood which obliterated another station, perhaps a

1'Agnes Kelly, Staff Assistant, Department of Education, American Museum of Natural History. 


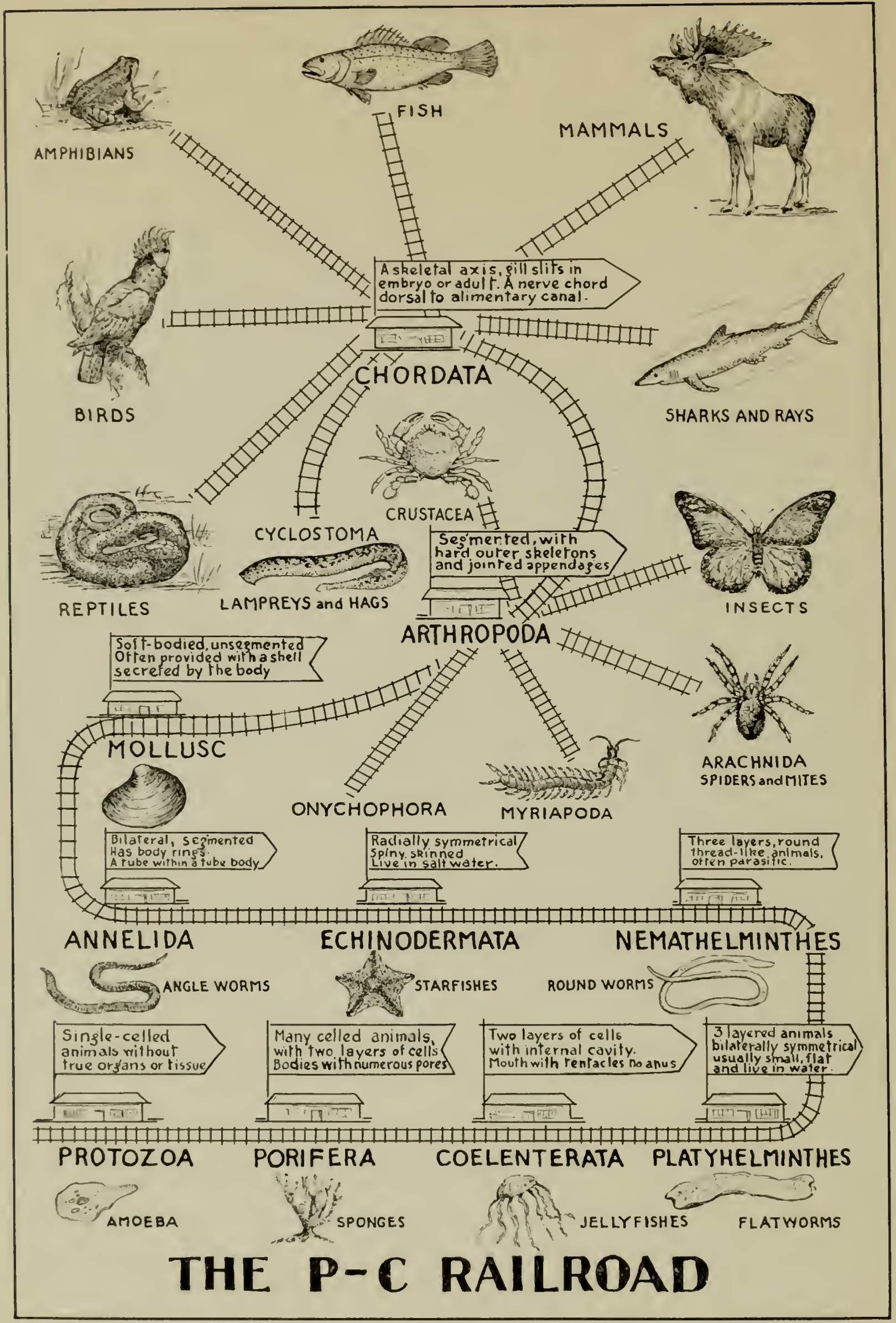

Fig. 12. 'The Protozoa-Chordata Railroad 
civil war or internal strife for the control of a division or the job of Stationmaster.

"To construct this Protozoa-Chordata Railroad in actual materials so that it will come within our scope of vision and our realm of comprehension, seems as absurd as playing dominoes with the stal's, but novertheless it can be done. Since each of us actually plays a different part in this animal railroad, each of us conceives of the whole in a different way. One way in which to smile at the unconquerable Laws of Nature, bring her 'children' to your fingertips and get a bird's-eye view of her Railroad, is to construct a plan of the railroad on cardboald. This can be done in sections using large sheets of white wrapping paper or a large white window shade. The scale, of course, is variable, but for legibility and ease in lettering, the minimum size is $27^{\prime \prime} \times 54^{\prime \prime}$. Plain India ink is probably best in indicating the stations and drawing the tracks. Stations may be painted in various Show Card colors, or may be indicated by caldboald or wooden structures glued to the base. A description of the station may be written on the roof of the station or on some flag or appropriate symbol artistically mounted. For example, the station CRUSTACEA may be explained by 'breathe by means of gills; the head and thorax are fused; two pairs of antennae; examples crabs and lobsters.' The station and its relation to the entire railroad is more clearly depicted by a real specimen of the station inhabitants. A real crab, for example, properly shellaced and glued to the base makes an effective representative of the population and makes the characteristics of the village more intelligible. The attractiveness of the entire railroad may be further enhanced by placing toy trains, signals, culverts, tunnels, trainmen, track-walkers, repair men, etc. in appropriate places. All of the accessories should have a definite meaning in fitting into the scheme. The 'repair man,' for example, may be described as an agent of regeneration of lost limbs, and the 'culvert' as an indication of animals overcoming natural obstacles for their preservation and propagation.

"There is ample opportunity in every phase of this Railroad for ingenuity and originality. It may easily tecome a more ccmplex project by making the entire thing in relief of modelling clay or plaster, showing the lows and highs of development by placing the mammals, for example, on the highest pinnacle."

So many important scientific principles are illustrated in a wellcared-for aquarium that the science room can scarcely afford to be withThe Balanced out one. The children who care for this aquarium will Aquarium soon discover something about the evaporation of water, the effect of sunlight on water plants, the necessity of providing plants to live along with the animal life for a balanced aquarium, and other important facts. They will also learn about the 
care of these plants and animals and how their structure fits them for life in the water. A rectangular jar makes the best aquarium and this can usually be secured from an electrician. Other shapes, however, are quite satisfactory. Do not attempt to use a jar with a tin bottom. If a cover is used to protect the aquarium from dust be sure that it is lifted at least a half inch above the top of the tank. This may be done in any of several ways, such as fastening small pieces of cork or a small piece of

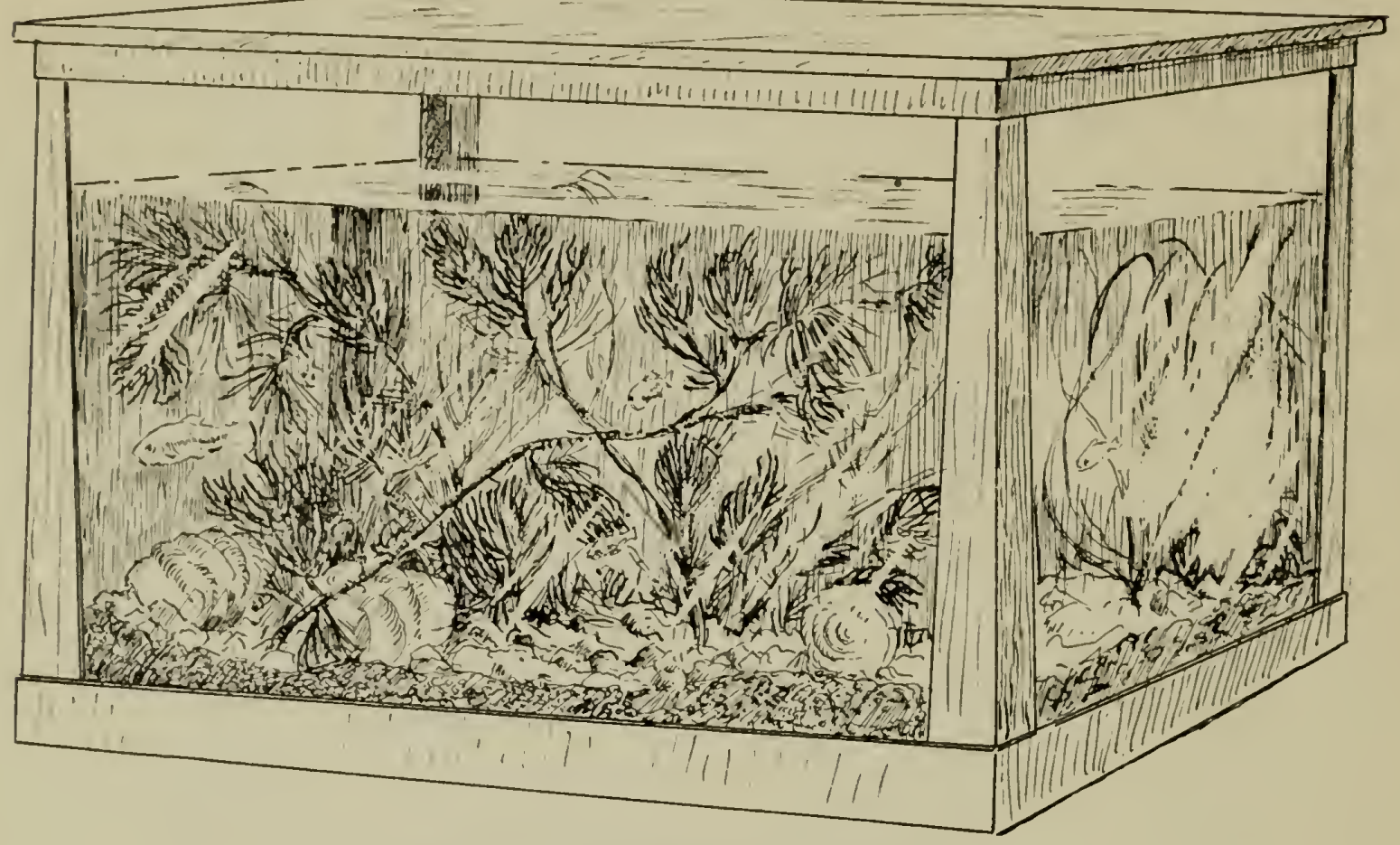

Fig. 13. A Balanced Aquarium.

felt on each corner. Make certain that these pices rest securely upon the rim of the jar below.

Although aquaria are important to a science room, do not forget that the terrarium is even more casily made and cared for and just as The Terrarium interesting and valuable from the scientific viewpoint. An old aquarium is very satisfactory. The little covered garden shown in the accompanying diagram is simple and inexpensive and can be made in many different sizes.

Materials for the terrarium construction are: cheap pan, rectangular in shape with straight sides about one inch high (one from the ten-cent store will do), glass (five pieces), adhesive tape, and green paint. To construct, fasten the pieces of glass together with the adhesive tape. Set in the pan below. Bind the edges of the cover with adhesive tape and paint the tape a pleasing soft green. For filling the terrarium place a layer of sand and gravel in the bottom, then a thinner layer of charcoal 
to keep the soil in grood condition. Cover this with a layer of rich soil in which you may plant your mosses, ferms, partridge berries and ot her woodsy plants to grow along with forms of animal life such as frogs, toads, and salamanders. Most plants suitable for life in a terrarium should not have much light nor be kept in a very warm place. Too much moisture is also undesirable because it favors the growth of molds and bacteria that cause decay.

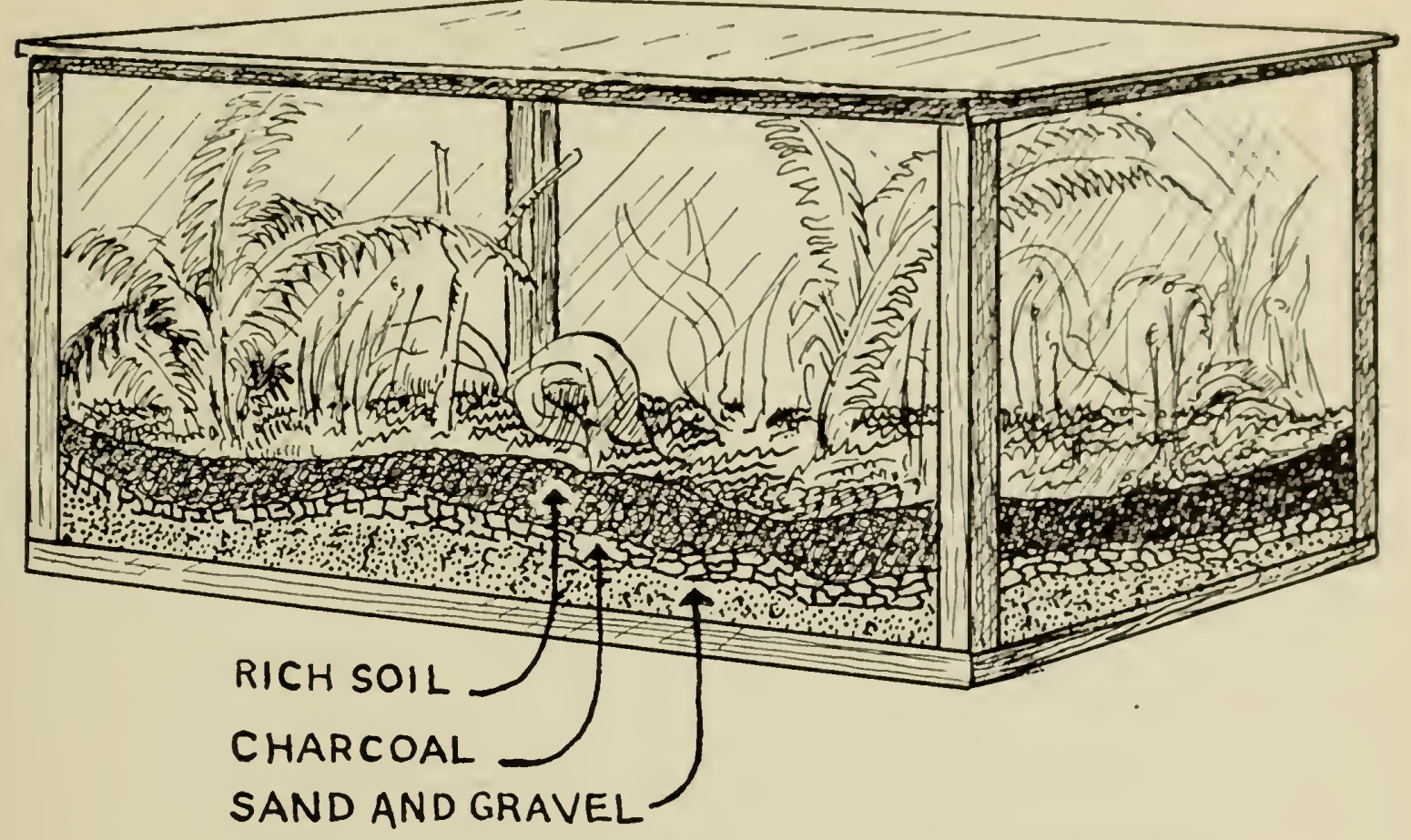

Fig. 14. A Diagram Showing Construction of a Terrarium.

Other favorite activities of children illustrate physical principles involved in everyday occurrences. Such a project is one which shows Projects how an aeroplane rises. A glass jar, with the bottom reIllustrating moved, is used as a wind tunnel. In this is suspended a Physical small wooden model of an aeroplane. Connect the jar to a Principals small wooden box used as the blower with an electric fan to provide the air current. Then arrange an electric button so an observer, by pressing the button, can work the model and see how the wings of the aeroplane are lifted.

Another interesting story is that of water power and waterways. With newspapers soaked in a mixture of plaster and water build up a model of hilly section of country including a stream which flows swiftly down to a miniature power house. Shellac all portions touched by the water. Here demonstrate the conversion of the mechanical energy in the water power into the electrical energy which will light a tiny bulb by using models of a water wheel to turn a small dynamo to produce the electric current needed for the tiny bulb. An interesting chart to 
accompany this would show on an outline map of the United States the location of important power and waterway projects.

Children always have great fun out of activities that "will work." The construction of an electrical nature chart is a simple matter and yet Electrical is very successful in teaching a great variety of facts. PicCharts tures of plants, fish, birds, mammals, famous men of science, etc., can be glued to a stout piece of cardboard, pressed wood or other material, with space left below each picture for an electrical contact point. For these contacts use brass bolts or radio taps. At the bottom of the board are the names of all the pictures, with a contact point arranged beside each name. Insulated bell wire is then used to connect the contact point of a picture with the contact point beside its name. The wiring is all done at the back of the board. A one and

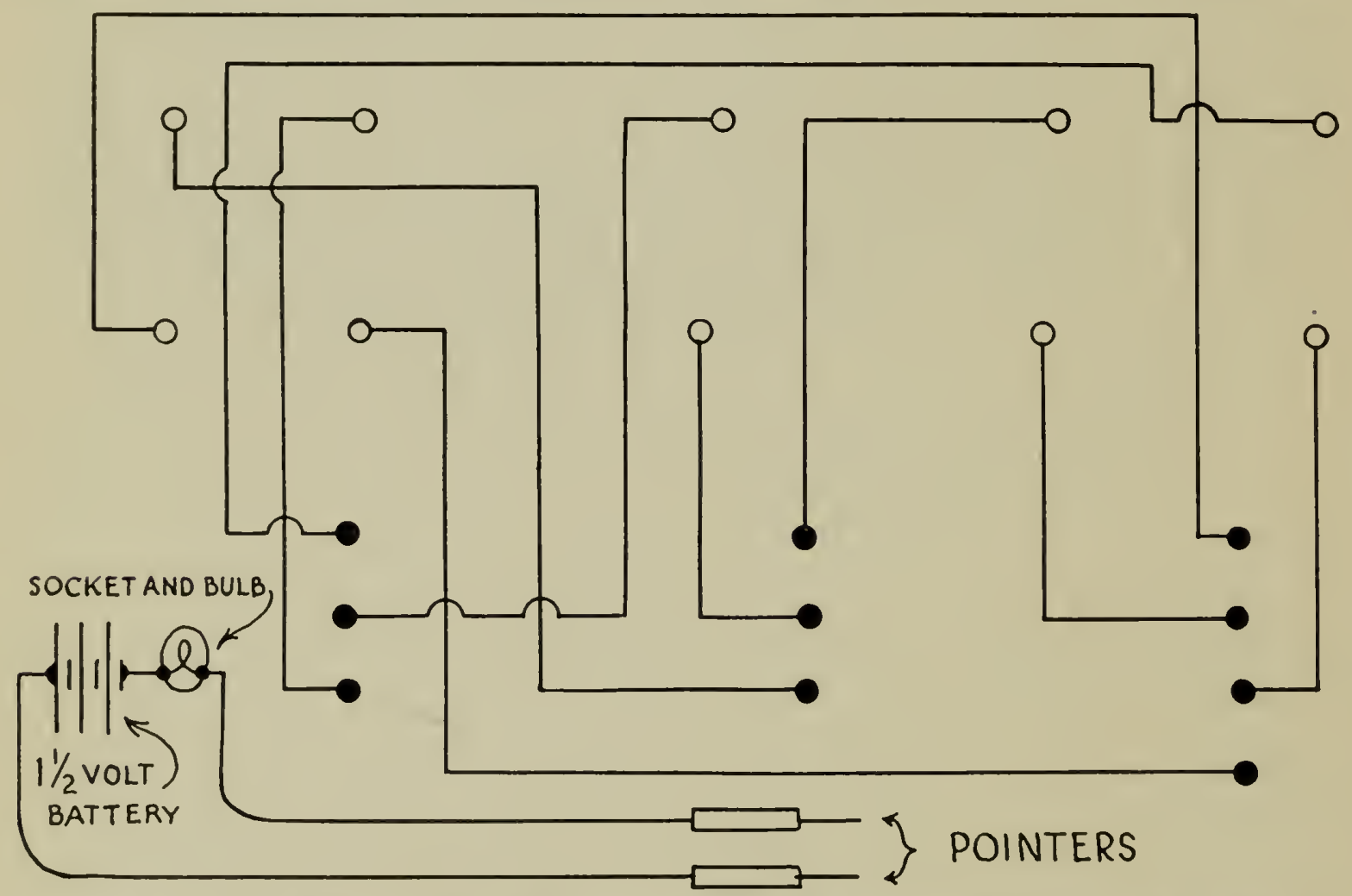

Fig. 15. Diagram Showing Construction and Wiring of an Electrical Chart.

one-half volt dry cell and a one and one-half volt bulb are so wired to two pointers that when the pointers are touched together, the circuit is completed and the bulb will light. The pointers can be constructed from short lengths of brass rod and handles made by wrapping tape around them. Radio plugs are ideal for this purpose but care must be used to connect the wire to the contact point that leads to the tip of the plug and not the one that leads to the side. Flexible wires which extend through the board are connected to the pointers. The bulb should be mounted so it will extend through the board or at least be placed in some position where its light may be seen from the face of the board. 
With the picture and its name wired together, when a person touches one pointer to the picture contact and the other to the correct name contact, the bulb will light. If any other contact than the correct one is touched, the circuit is not closed and the bulb does not light. 'The diagram in figure No. 15 shows the appearance of the back of a board of such an electrical game, indicating the wiring needed for ten pictures and names, also the location of the battery and bulb. Practically all the materials needed for such a chart may be purchased in any ten-cent store. The parts required are as follows.:

Contact points (Number depends upon number of pictures used.)

One $1_{1 / 2}^{1 / 2}$ volt dry cell

One $1_{/ 2}^{1 / 2}$ volt bulb and socket

One roll insulated bell wire

$1 \frac{1}{2}$ yards flexible strand wire

Two cheap radio plugs

There are innumerable other projects which might be described but the basic techniques involved in their construction have been given, so the problem of preparing other projects is simply a matter of adapting these techniques to the special materials the children wish to use, always keeping in mind the basic principle in all of this work, namely, that accuracy and simplicity in the story represented are the first considerations. Lack of special equipment in a school will not hinder enthusiastic boys and girls from expressing their ideas in many interesting concrete forms.

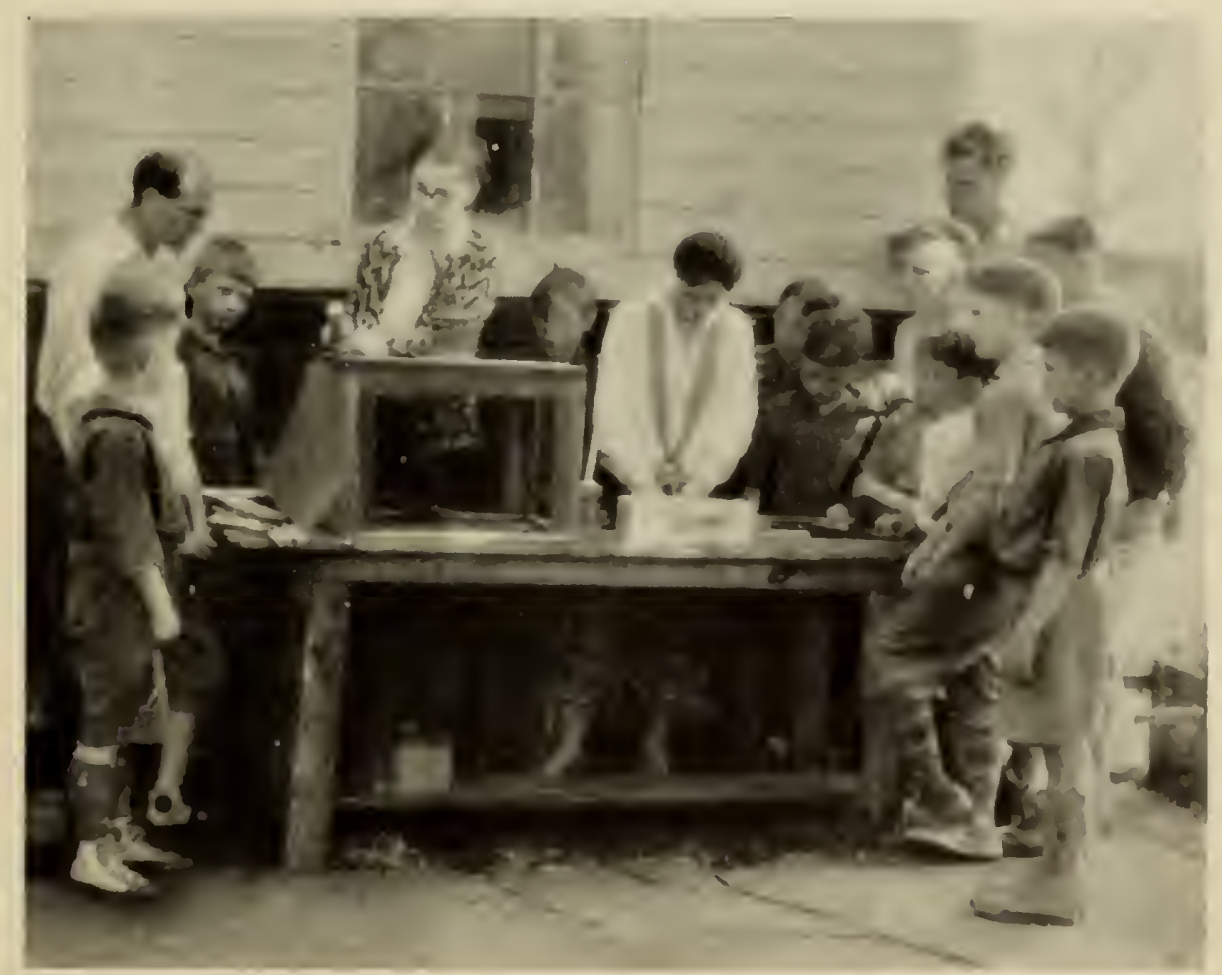

Fig. 16. Simple Equipment 



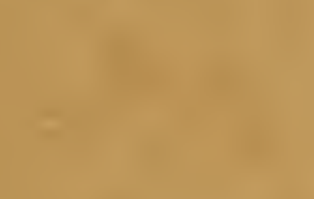

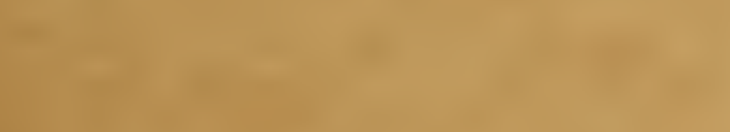

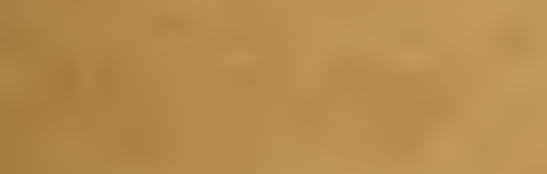

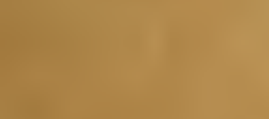

-

(a)

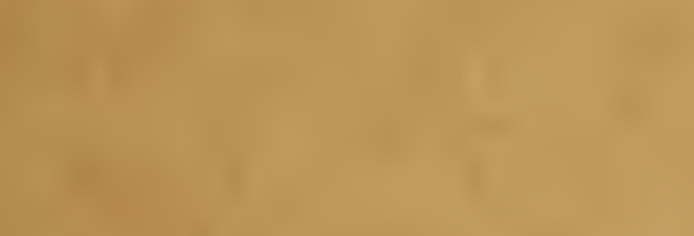

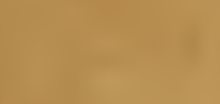
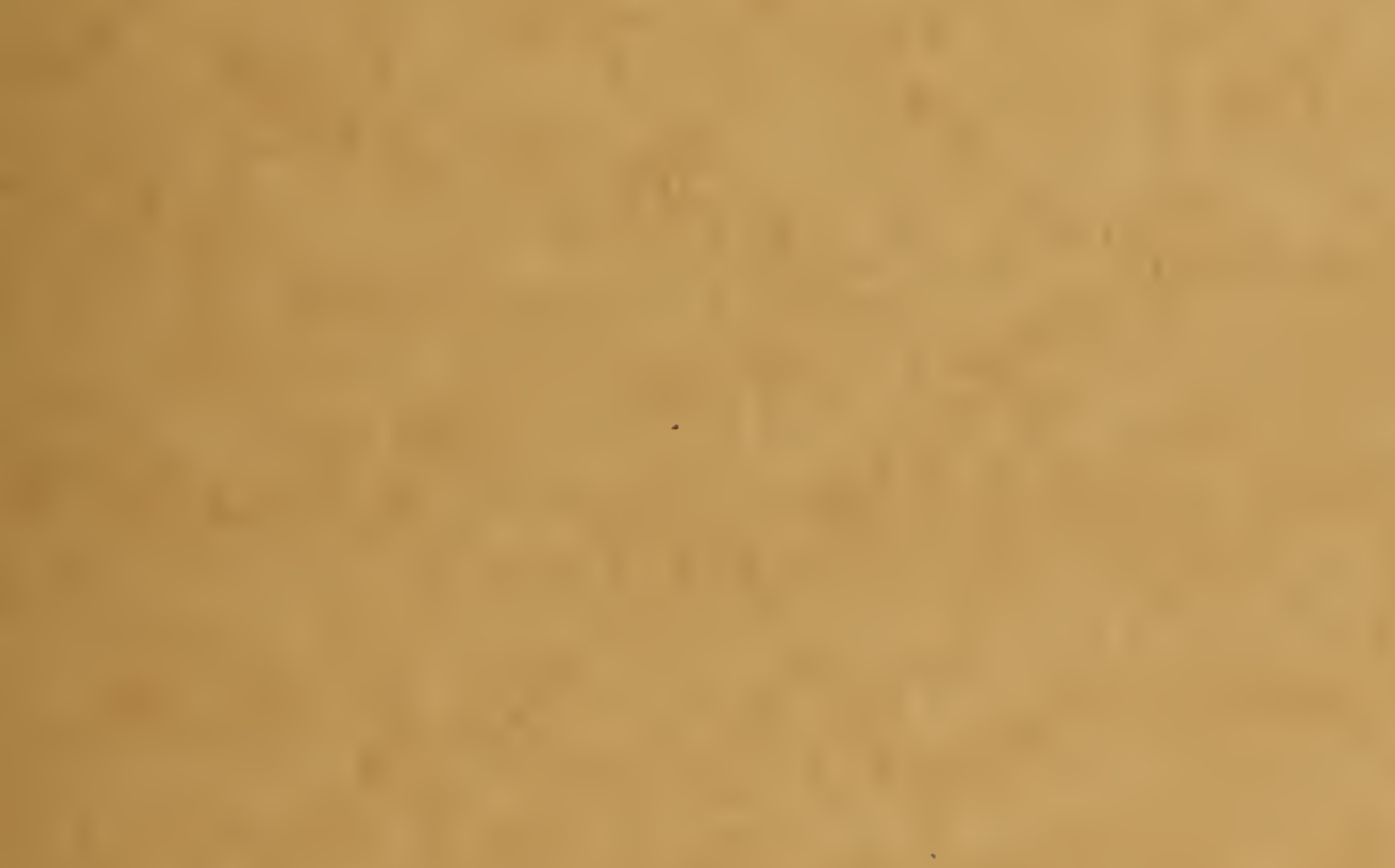

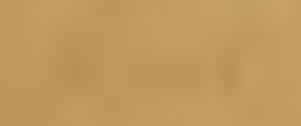

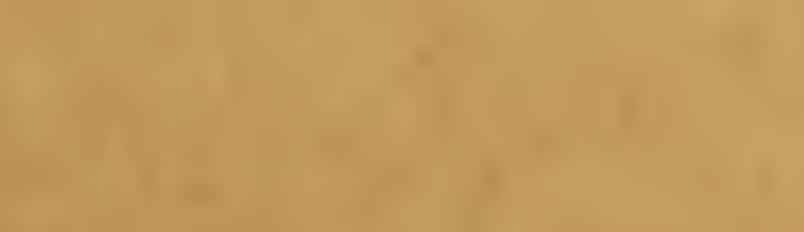


